DOI: https://doi.org/10.47405/mjssh.v6i9.1007

\begin{tabular}{|c|c|}
\hline 4 & Malaysian Journal of Social Sciences and Humanities (MJSSH) \\
\hline $\begin{array}{l}\text { Malaysian Juoural of } \\
\text { Social ccciecces and }\end{array}$ & Volume 6, Issue 9, September 2021 \\
\hline (MJ-sSH) & e-ISSN : 2504-8562 \\
\hline & $\begin{array}{l}\text { Journal home page: } \\
\text { www.msocialsciences.com }\end{array}$ \\
\hline
\end{tabular}

\title{
Progression In Recognising Diversity, Fostering Inclusiveness and Equality in Malaysia
}

\author{
Naresh Kumar Samyi,2, Ahmad Faisal Mahdi ${ }^{3}$, Nur Hazelen Mat Rusok ${ }^{3}$ \\ ${ }^{1}$ Faculty of Entrepreneurship and Business, Universiti Malaysia Kelantan (UMK) \\ 2Faculty of Business, Management and Information Technology, Asia Metropolitan University \\ ${ }^{3}$ Faculty of Business and Management, Universiti Teknologi MARA
}

Correspondence: Naresh Kumar Samy (naresh@umk.edu.my)

\begin{abstract}
Men and women are both inherently equal; the issue is that they do not always have equal rights in practice, but the supporting pieces of evidence are limited. The Malaysian Constitution, which guarantees civil rights and equality, includes state institutions dedicated to maintaining gender equality and policies designed to that end. However, adverse reports criticised the judicial system and emphasised fair chances for all, supporting and appreciating differences, and ensuring equal access. Anti-discriminatory practices are a contentious subject, but there must be an assessment to see if today's youth have retained a memory of the past and a sense of good values and proper mechanisms for peaceful coexistence in the pursuit of social equity and diversity and inclusivity in Malaysia. The opportunities for Malaysia to promote human rights, eliminate gender-based violence and injustice are more excellent now than they have been in the country's history. The study's intriguing results are directly linked to practice and lead to several other routes for further investigation.
\end{abstract}

Keywords: diversity, education, inclusivity, gender equality, human rights, Malaysia

\section{Introduction}

The Federal Constitution of Malaysia is the highest law in the country, protects fundamental liberties (Articles 5, 7, 8 - 13) and declares that any law that conflicts with the Constitution is null and invalid. Islam is the primary and official religion of the Federation, according to the Constitution. Knowledge of the Federal Constitution, Civil and Islamic laws that relate to the extent and substance of human rights, and the link between these rights and human dignity and survival are essential at any stage in one's life as a Malaysian citizen. Furthermore, understanding the domestic mechanisms to redress human rights violations and promote human rights is critical, particularly for the new generation of Malaysians who will carry on the country's heritage of human rights protection and promotion.

Human rights education is an indispensable element of general education in Malaysia's multi-ethnic culture, and it is mandatory. From pre-school to higher education levels, the best practises, moral obligations, and societal rights following Malaysia's legislative system thought directly and indirectly to form responsible citizens who value human dignity, equality, harmony, and a peaceful work-life balance. Due to Malaysia's status as a member of the United Nations and its adherence to the Universal Declaration of Human Rights (UDHR), the nation recognises international practices of equality and fairness, with the caveat that social rights to be in protection within the framework of the 
Federal Constitution and Islamic principles. Notably, some levels of western orientation and worldwide recognition of human equality and rights are not present in Malaysia. Human rights have always been in reality, but they have not been recorded adequately and distributed worldwide since each country have restrictions by its legislative system, distinct from the others. Respect and dignity accorded to the fundamental freedoms of men and women and children and the elderly. Beginning in 1948 and continuing today, more country-based reports have been created, disseminated, and documented by the United Nations to enhance global solidarity and preserve fundamental rights for all human beings. A human rights knowledge database advanced, and chances to learn about best practices were made available.

Every culture, tradition, and civilisation has human rights ingrained in it. It is constantly evolving, and as a result, understanding the organisations engaged in promoting and preserving civil liberties is extremely important for the whole human race. The expansion of governmental and non-governmental organisations (NGOs) aims to foster an environment in which diverse races, religions, traditions, and belief systems must cherish to promote peaceful living and a more healthy socio-cultural advancement. Justice, tolerance, and collaboration are only a few factors that contribute to a more equitable and non-discriminatory social structure, which ultimately leads to world peace.

"SUHAKAM" was founded on April 3, 2000, as the Human Rights Commission of Malaysia, under the Human Rights Commission Act 1999 (act 597). The start of SUHAKAM can be traced to Malaysia's election to the United Nations Commission on Human Rights (UNCHR) by the United Nations Economic and Social Council in 1993-1995 when it served as a member of the commission for three years. SUHAKAM's tasks include promoting awareness of and educating people about human rights, helping the government draught laws and procedures, and investigating human rights violations (Kim, Abdullah \& Kheng (2007). Several registered organisations in Malaysia are actively involved in conveying human rights concerns to the general public. Despite this, only a few organisations with human rights aims and activities spread across the general public. Besides SUHAKAM, some of the registered organisations are Persatuan Promosi Hak Asasi Manusia (PROHAM), Tenaganita, Suara Rakyat Malaysia (SUARAM), Aliran Kesedaran Negara (Aliran), Global Movement of Moderates (GMM), National Human Rights Society (HAKAM) and Malaysian Bar Council.

At this time, Malaysia has implemented National Women Policy and Action Plan (2009-2015), and in nearly every area, the subsequent national development plans have included substantial policy efforts for women's progress. All of which deal with gender equality and progress under the umbrella of the Islamic faith (Baqutayan, 2020, Jalal et al., 2020; Lim, 2019; Saleh, 2020). The government form several committees to bridge the gap between Malaysia's obligations to the Convention on the Elimination of Discrimination Against Women (CEDAW). The governmental working groups provide counsel, information, and assistance to women and organisations on equal opportunities and rights in the professional environment. It represents Malaysia's overall approach to gender equality, particularly Malaysia's commendable position on women's rights and equitable treatment. Gender-supportive behaviours would significantly influence by the provision of educational possibilities (Thijs et al., 2019). For these instances, a more rigorous work plan and research would provide a more thorough assessment.

Traditionally, the general cultural norms that hinder women from entering politics and the economy have now ended and encourage women to engage in all activities. Sustainable Developments Goals (SDGs) contain elements of women, and they serve as a guide for many nations, including Malaysia. The OECD (2017) report emphasises that existing studies have thus far been unable to grasp the significant variances in national gender imbalances. Review on several available sources carried to understand better the current state of gender equality. Aminuddin (2020) examined ethnic disparities and the likelihood of people engaging in racial and religious prejudice in Malaysia. The feeling uncomfortable with individuals of a different race or religion as neighbours surveyed to justify the discrimination. People of various ethnicities discriminate against others, according to the study. The federal Constitution of Malaysia states that both men and women have equal rights of citizenship. Noting that the Malaysian Constitution needed modification to provide women with the same rights as 
males regarding their marital citizenship status, Saleh et al. (2021) also said that this is required to uphold equal rights for everyone correctly.

In the monitoring report Gender Equality in Malaysia, Hui (2020) writes that Malaysia is comparatively free of gender inequity, nevertheless highlighted the fact that there are few examples of gender inequality in the country. The report encourages NGOs and the government to continue fighting discrimination and violence, improving admittance to sexual and reproductive health and rights and providing women and girls with equal opportunities in all aspects of life. It also stresses the importance of advancing this work even further. Simirlarly, Weimann-Sandig (2020) identified the degree of disparity between men and women in Malaysia as being dependent on opportunities for employment and economic gains. The author believes that reviewing gender equality legislation and other legal entitlements is essential in order to reflect inclusive behaviour in the job market. In reality, many government regulations exist to enhance equality, but the implementation is not smooth and rarely a high priority.

The Global Gender Gap Report measures how nations have progressed towards gender parity by examining the gender gap across 153 countries. Malaysia ranked 112th out of 150 nations in the Global Gender Gap Index in 2021, as opposed to 104th out of 153 countries in 2020 (World Economic Forum, 2020, 2021). The report focuses on gender equality by considering four variables: economic participation and opportunity, educational attainment, health and survival, and political empowerment. Progress in educational attainment $(r a n k=70 / 150$; parity score $=0.994)$ and health and survival (rank=74/150; parity score $=0.972$ ) have been found in Malaysia to be superior overall. The nation's gender equality has reached (parity score $=1$ or above) for healthy life expectancy and secondary and tertiary education enrollment.

Nevertheless, the ranking and parity scores for political empowerment (rank=128/150; parity score $=0.102)$ and economic participation and opportunity $(r a n k=104 / 150$; parity score $=0.638)$ fall outside the favourable range. Exactly how it was in 2020. Notably, Malaysia is behind its neighbours in gender equality. Therefore, the World Bank advised the Malaysian government to "proceed with urgency" to address this critical issue for economic equality between the genders (Chung, 2021). The study proposes that the Malaysian government reevaluate current laws and regulations to find new ways to enact change.

Women in Malaysia have gained more access to education and understanding of their constitutional rights, improving their conditions. However, Saleh et al. (2020) alert that legislation has eliminated discrimination against women throughout the years, but no precise definition of such discrimination has developed. By implementing a positive gender-sensitive culture and encouraging males to engage in all activities geared towards gender equality, prejudice against women eliminated states Saleh et al. While considerable advances achieved in educational possibilities and economic liberalisation. Women's involvement has seen a boost. Abiddin and Ismail (2018) note that significant problems remain because of structural, cultural, and institutional roadblocks. Substantial public policy effort is required, together with enthusiastic leadership in promoting gender-inclusive practices.

Jalal et al. (2020) echo previous discussions when they demonstrate that the existing gender equality practices are far from enough and should be addressed consistently throughout Malaysia's organisations. The Malaysian government encouraged to make significant efforts to increase the involvement of women in all aspects of decision-making, in both the workplace and in other areas such as politics. Encouraging women and inspiring them to succeed on a deeper level in their professional and personal lives is undoubtedly a priority (Chen \& Koh, 2021, Lim, 2018, 2019). Having a voice elevates the status of women in society, and with increased prominence, they rise to greater heights in their many endeavours. To Baqutayan (2020), it appears that empowering women can help break down gender inequality and that they must utilise personal, relational, and environmental forms of empowerment to bring about gender equality. Goal 5: achieve gender equality and empower all women and girls; SDGs say the same. 
As of this moment, the assertion that Malaysian women are behind males primarily due to cultural traditions is rebuttable. It may well be an inaccurate notion about Malaysian women today experiencing an unprecedented advancement in their engagement, despite the significant gap in the number of women in economic, political, educational, and healthcare fields. Advancing women's educational, health care, labour, and political opportunities would help strengthen the economy and benefit society. While people have become more conscious of gender equality, simple to sophisticated surveys are necessary to determine if people in Malaysia have acquired information about fundamental rights, gender equality and institutions that govern human rights.

On regular observation, one could note that the flood of information on social media significantly impacted the attention of younger people regarding their duties and responsibilities with regards to human rights. Further, at higher education institutions, students must be well-versed in socio-cultural aspects since course requirements cover civil liberties. In today's more civilised society, expected students to determine instances of discrimination based on gender, race, skin colour, country of origin, ethnicity, and religion. It is essential to periodically check to see if views on human rights are favourable and if there is knowledge of the presence and operations of various human rights groups among the younger generations. This paper reports the investigation carried out amongst the younger nations of the country - students of the higher learning institutions.

\section{Methodology}

The study used a non-probability sampling method to choose final-year undergraduate students as subjects. Using Krejcie and Morgan's (1970) sample size determination table, 384 respondents were selected to reflect a significant population. The researchers modified a survey questionnaire from a UNDP study report on Yemen's national human rights capacity (Arab States-UNDP, 2014). The UNDP study report is helpful. The researchers recognise the need to replicate the study in Malaysia using identical survey items that are feasible and easy to conduct. The current study does not seek to compare the results of Yemen samples with Malaysian samples due to the study's nature. For categorical variables, frequencies and percentages are used to describe the findings. Cross-tabulations with chi-square significance testing were helpful in find significant gender differences.

\section{Findings}

One hundred sixty-nine males (44 per cent) and 215 women answered the survey's questions (56 per cent). Most survey participants who were able to complete the survey were female. Although women have assumed positions of dominance in recent years at Malaysian universities due to the country's financial support for education without regard to gender, the results reflect reality. Based on this research, the bulk of respondents fall between the ages of 20 and 29. Millennials (the next generation) in Malaysia regard as younger adults. Following the surveys' findings, results are available in the following sub-parts.

\section{Attitudes Regarding Different Social Groups}

One of the survey objectives was to measure attitudes towards specific social issues that impact Malaysian enjoyment of human rights. Respondents asked about how they would react if a foreigner moves into the home next to theirs. The findings indicate that majority of the male $(69.0 \%)$ and females $(69.5 \%)$ agreed with the same treatment to foreigners. In comparison, both genders $(20.6 \%)$ had stated that they would prefer a specific limit with the foreigner. Besides, a small number of the respondents $(n=39,10.2 \%)$ said they would avoid foreigners. Religion proved to be a more sensitive subject. However, the respondents asked if other religions/races were to move into the home beside them, how would they react? The study shows a majority of the respondents $(92.2 \%)$ will give the same treatment to another religion/race. Only $5.2 \%$ of the total respondents stated they would have certain limits, whereas (2.6\%) answered they would avoid. 
Regarding reactions towards foreigners, the Chi-Square statistics revealed no statistically significant differences between males and females when comparing them based on gender: X2 $(2, \mathrm{~N}=$ $384)=2.679, p=.262$. On the other hand, significant differences in responses for reactions on different religions and races in Malaysia appears, $\mathrm{X} 2(2, \mathrm{~N}=384)=3.599, \mathrm{p}=.002$. Table 1 provides a summary of the results.

Table 1: Reactions towards foreigners, other religions and races in Malaysia

\begin{tabular}{lllllll}
\hline Reactions & $\begin{array}{l}\text { Male } \\
\mathbf{n}\end{array}$ & $\mathbf{\%}$ & $\begin{array}{l}\text { Female } \\
\mathbf{n}\end{array}$ & $\mathbf{\%}$ & $\begin{array}{l}\text { Total } \\
\mathbf{n}\end{array}$ & $\mathbf{\%}$ \\
\hline $\begin{array}{l}\text { Reactions towards } \\
\text { foreigners* }\end{array}$ & 174 & 100.0 & 210 & 100.0 & 384 & 100.0 \\
$\begin{array}{l}\text { same } \\
\text { certain limits }\end{array}$ & 120 & 69.0 & 146 & 69.5 & 266 & 69.3 \\
$\begin{array}{l}\text { avoid } \\
\begin{array}{l}\text { Reactions towards other } \\
\text { religions and races** }\end{array}\end{array}$ & 32 & 18.4 & 47 & 22.4 & 79 & 20.6 \\
$\begin{array}{l}\text { same } \\
\text { certain limits }\end{array}$ & 174 & 12.6 & 17 & 8.1 & 39 & 10.2 \\
avoid & 156 & 89.7 & 198 & 94.3 & 354 & 92.2 \\
\hline
\end{tabular}

$*$ Note: $* \mathrm{X}^{2}(2, N=384)=2.679, p=.262 ; * * \mathrm{X}^{2}(2, N=384)=3.599, p=.002$

\section{Gender-Based Violence}

Gender-based violence (GBV) is physical, sexual, or psychological abuse directed at women or girls. Such violence can occur in public or private. There is little knowledge of the prevalence of GBV and social attitudes regarding such violence in Malaysia. Several questions about GBV were included in the survey to address this and allow agencies working towards raising awareness about GBV to assess its success. First, respondents asked whether they had partaken in the activities to combat GBV. Only a tiny percentage of male and female respondents $(2.1 \%)$ participated in combating GBV. Almost all the respondents (97.9\%) stated they had never taken part in such activities. Surprisingly the results reveal that women respondents did not actively participate in actions against GBV. Also detected a similar finding amongst male respondents. When comparing men and women, the Chi-Square statistics revealed no statistically significant variations in the general level of participation against GBV. The results are in Table 2. It signifies that there are no pressing issues of GBV that induce reactions among Malaysians. Big applause to the nation in a preserving atmosphere free of discrimination, gender equality, and inclusiveness upscaled. However, the findings are students' perceptions, and perhaps there are chances for a reverse opinion if the survey directs to a different set of respondents.

Table 2: Participation against gender-based violence (GBV)

\begin{tabular}{lllllll}
\hline Participation in GBV & $\begin{array}{l}\text { Male } \\
\mathbf{n}\end{array}$ & $\mathbf{\%}$ & $\begin{array}{l}\text { Female } \\
\mathbf{n}\end{array}$ & $\mathbf{\%}$ & $\begin{array}{l}\text { Total } \\
\mathbf{n}\end{array}$ & $\mathbf{\%}$ \\
\hline Self participation in GBV* & 174 & 100.0 & 210 & 100.0 & 384 & 100.0 \\
Yes & 3 & 1.7 & 5 & 2.4 & 8 & 2.1 \\
No & 171 & 98.3 & 205 & 97.6 & 376 & 97.9 \\
$\begin{array}{l}\text { Participations of family, } \\
\text { friends and others in }\end{array}$ & 174 & 100.0 & 210 & 100.0 & 384 & 100.0 \\
GBV** & & & & & & \\
Yes & 5 & 2.9 & 9 & 4.3 & 14 & 3.6 \\
No & 141 & 81.0 & 158 & 75.2 & 299 & 77.9 \\
Not Sure & 28 & 16.1 & 43 & 20.5 & 71 & 18.5 \\
\hline
\end{tabular}

*Note: $* \mathrm{X}^{2}(2, N=384)=2.089, p=.452 ; * * \mathrm{X}^{2}(1, N=384)=2.239, p=.142$ 


\section{Attitudes Regarding Gender Equality}

Moving beyond GBV, the survey attempted to address questions of gender equality on a multitude of human rights. For a more nuanced and focused understanding of particular issues of equality, diversity and inclusivity, questions are phrase differently. Table 3 demonstrates the percentage of respondents reporting that they support gender equality for each given right. The study results show that the respondents view men and women should have equal rights in all aspects listed in Table 3. Equal rights for both gender before the courts, family matters and owning property were the top three items scored high. Meanwhile, assessment on divorce scored almost balanced between the three categories with scores ranges between $31.3-35.2$ per cent. The young respondents seem to think differently than the general public, probably the exposure of human dignity and respect getting a place in their heart-brain.

Table 3: Assessment of Gender Equality ( $\mathrm{N}=384)$

\begin{tabular}{|c|c|c|c|c|c|c|}
\hline \multirow[t]{3}{*}{ Items } & \multicolumn{6}{|c|}{ Opinion } \\
\hline & \multicolumn{2}{|c|}{$\begin{array}{l}\text { Men should have } \\
\text { greater rights }\end{array}$} & \multicolumn{2}{|c|}{$\begin{array}{l}\text { Women should } \\
\text { have greater } \\
\text { rights }\end{array}$} & \multicolumn{2}{|c|}{$\begin{array}{l}\text { Both should have } \\
\text { equal rights }\end{array}$} \\
\hline & $\mathbf{n}$ & $\%$ & $\mathbf{n}$ & $\%$ & $\mathbf{n}$ & $\%$ \\
\hline Before the courts & 6 & 1.6 & 5 & 1.3 & 373 & 97.1 \\
\hline In family matters & 48 & 12.5 & 39 & 10.2 & 297 & 77.3 \\
\hline $\begin{array}{l}\text { In owning property (including } \\
\text { houses, land, vehicles, etc.) }\end{array}$ & 50 & 13.0 & 44 & 11.5 & 290 & 75.5 \\
\hline $\begin{array}{l}\text { Being a candidate in local and } \\
\text { parliamentary elections }\end{array}$ & 60 & 15.6 & 49 & 12.8 & 275 & 71.6 \\
\hline In taking part in the government & 72 & 18.8 & 58 & 15.1 & 254 & 66.1 \\
\hline Regarding work & 81 & 21.1 & 72 & 18.8 & 231 & 60.2 \\
\hline $\begin{array}{l}\text { In choosing when to have } \\
\text { children }\end{array}$ & 56 & 14.6 & 129 & 33.6 & 199 & 51.8 \\
\hline With regard to inheritance & 88 & 22.9 & 108 & 28.1 & 188 & 49.0 \\
\hline Regarding custody of children & 78 & 20.3 & 127 & 33.1 & 179 & 46.6 \\
\hline Regarding divorce & 129 & 33.6 & 120 & 31.3 & 135 & 35.2 \\
\hline
\end{tabular}

\section{Sources of Knowledge on the Human Rights Commission}

SUHAKAM's primary purpose is to promote human rights education, provide recommendations on law and policy, and conduct investigations into human rights concerns in Malaysia (Kim, Abdullah \& Kheng, 2007). Thus, the respondents in this study ask to inform the significant source of knowledge about SUHAKAM. Both male and female respondents reported that the Internet $(39.8 \%)$ and newspapers (print/electronic) $(18.5 \%)$ were the primary sources of information about SUHAKAM. Teachers also reported playing a significant role in disseminating Information on SUHAKAM (17.7\% of the respondents). Teachers occupy a crucial position in the educational process and substantially influence the shaping of the young mind.

Respondents noted receiving better information from radio (10,4\%) than television (1\%), which scored the least among all the sources of information on human rights. Moreover, less than $10 \%$ of the respondents have received news of SUHAKAM from their respective relatives and SUHAKAM activities. Promoting human rights through social media, mobile communication, and digital networks has become a trend in today's modern world. SUHAKAM is a valuable body for human rights protection in the eye of the respondents. Thus, it is encouraged to get to the masses and disseminate human rights efforts via the media that the current generation is more favourable. The Chi-Square statistics showed significant differences in the level of human rights knowledge when compared by gender: $\mathrm{X}^{2}(6, N=384)=13.635, p=.034$. Table 4 presents the results on sources of knowledge on SUHAKAM by gender. 
Table 4: Sources of Knowledge on SUHAKAM by Gender $(n=384)$

\begin{tabular}{lllllll}
\hline Source & Male & \multicolumn{3}{c}{ Female } & \multicolumn{3}{c}{ Total } \\
\cline { 2 - 7 } & $\mathbf{n}$ & $\mathbf{\%}$ & $\mathbf{n}$ & $\mathbf{\%}$ & $\mathbf{n}$ & $\mathbf{\%}$ \\
\hline Internet & 76 & 43.7 & 77 & 36.7 & 153 & 39.8 \\
Newspaper & 38 & 21.8 & 33 & 15.7 & 71 & 18.5 \\
Teachers & 26 & 14.9 & 42 & 20.0 & 68 & 17.7 \\
Radio & 14 & 8.0 & 26 & 12.4 & 40 & 10.4 \\
Suhakam activities & 12 & 6.9 & 12 & 5.7 & 24 & 6.3 \\
relative & 5 & 2.9 & 19 & 9.0 & 24 & 6.3 \\
Television & 3 & 1.7 & 1 & 0.5 & 4 & 1.0 \\
Total & 174 & 100.0 & 210 & 100.0 & 384 & 100.0 \\
\hline
\end{tabular}

Note: $\mathrm{X}^{2}(6, N=384)=13.635, p=.034$

\section{Preference on human rights organizations}

Respondents asked to whom they would turn if they felt their rights violated. SUHAKAM (32.4\%) and the Police $(24.3 \%)$ are the top priority for female respondents compared to males who select NGOs. This finding shows the female respondents had more trust in the government compared to the male respondents. Nevertheless, the second choice of organisation among the male respondents $(24.1 \%)$ were NGOs. The aggregate responses for top preferences are SUHAKAM (28.6\%), followed by NGO's $(25.2 \%)$, and Police $(20.6 \%)$. A small percentage $(0.8 \%)$ of respondents stated that they would consult their relatives for advice if they have problems related to human rights issues. Interestingly, none of the respondents states they prefer to be quiet and live with it. The aggregate preference scores show that NGOs play almost equal roles in addressing human rights issues and ease accessibility for assistance when they feel their rights get violated. The Chi-Square statistics revealed statistically significant variations in the responses by gender, $\mathrm{X}^{2}(5, N=384)=18.902, p=.002$. Table 5 presents the full results.

Table 5: Preferred organisation for consultation on human rights issues $(n=384)$

\begin{tabular}{lllllll}
\hline Source & Male & & Female & \multicolumn{3}{l}{ Total } \\
\cline { 2 - 7 } & $\mathbf{n}$ & $\mathbf{\%}$ & $\mathbf{n}$ & $\mathbf{\%}$ & $\mathbf{n}$ & $\mathbf{\%}$ \\
\hline Suhakam & 42 & 24.1 & 68 & 32.4 & 110 & 28.6 \\
NGOs & 50 & 28.7 & 48 & 22.9 & 98 & 25.5 \\
Police & 28 & 16.1 & 51 & 24.3 & 79 & 20.6 \\
Press / Media & 33 & 19.0 & 37 & 17.6 & 70 & 18.2 \\
Legal Advisors & 18 & 10.3 & 6 & 2.9 & 24 & 6.3 \\
Relative & 3 & 1.7 & 0 & 0.0 & 3 & 0.8 \\
Total & 174 & 100.0 & 210 & 100.0 & 384 & 100.0 \\
\hline
\end{tabular}

Note: $\mathrm{X}^{2}(5, N=384)=18.902, p=.002$

\section{Discussion}

The majority of the respondent stated that they would provide the same treatment towards the foreigners and other religions or races in Malaysia. These may suggest that the younger generations of Malaysia are aware of the importance of respecting each other, cooperating, and establishing a harmonising living environment in Malaysia. Harmonisation of Malaysian human rights law with international human rights orders without compromising the Asian values are encouraged. Malaysia should maintain the equal-opportunity approach to all Malaysian citizens to gain civil, political, economic, social, and cultural rights. Besides, the equal opportunities provided by the government need publicity to the general public. Standard mass media could be helpful to disseminate such information. 
A campaign can afford to create awareness of the importance of living together and achieving life goals. Some of the activities in this campaign would be exposure to national culture and its interaction with international culture. Seminars or workshops on cultural competencies include the national and international cultural competencies required to achieve synergy among the community. This campaign would involve different people from the government, NGOs, and independent volunteers at many levels. The action further can instil cultural competency knowledge through the education system to start at the early stage - pre-schools. There should be Inter-Cultural Dialogues amongst the leaders and the citizens to embrace the diversity of culture, tradition and believes in Malaysia. Dialogues help retrieve information on the cultural gaps between religions or among the locals and the foreigners in the country. Such afford or steps in clarifying doubts or taking away the negative perceptions on a specific group of people would be significant to sustain the harmony among the locals and the foreigners.

A small percentage of respondents had heard about someone who has participated in activities to combat GBV. Moving beyond GBV, both the gender collectively believe that men and women should have equal rights in social, economy and politics. It is timely that current NGOs and SUHAKAM form a specific task force under the youth movement wings forever to safeguard anyone in Malaysia with concerns on GBV. In this endeavour, memberships should be extended to schools, universities, and the general public to take part with this group on a volunteers basis, striving towards a violencefree nation.

The holistic network between the Ministry of Women and family, Ministry of Youth and Sports with SUHAKAM and other NGOs should combat GBV persistently with increased participation of youths. NGOs had managed to gain a high level of trust among the public, so creating strategic ties will ease the GBV issues. More relevant activities such as debate competitions should be organised and participated by the NGO's and ministries to enhance the community's level of awareness on Women's rights and needs in making decisions.

Recognising the community's achievements that serve human rights is an effective way of engaging the nation and ensuring that everyone strives to get involved in social activities related to human rights. Provision of awards to those who have demonstrated their excellence; NGOs or communitybased organisations that have achieved remarkable results; journalists, and so forth are encouraged. The mass media is an excellent platform for a call for nominations for an award, or a special task force under SUHAKAM should equally recommend awards for those who deserve it.

Despite notable general criticism on the SUHAKAM's performance, most of the respondents in this study comfortable and trust SUHAKAM, followed by NGOs and other entities to provide continuous consultation for remedies in the event of any human rights violations. We recommend that research to identify the impact of SUHAKAM conducted on individuals, organisations and communities. The current study had revealed that many respondents are not aware of the SUHAKAM's functions. Less information reaches the public on the activities carried out by SUHAKAM. Indeed, SUHAKAM news in primary media only appears if any human rights cases are highlighted or brought forward to the court. The public's awareness of SUHAKAM lacked and needs a constructive action plan to propagate the activities and efforts.

E-News are an excellent source of information and awareness tools. SUHAKAM is encouraged to produce newsletters on weekly basis reporting issues about human rights. E-Newsletters can also be used as awareness-raising gears for various civil rights issues within Malaysia and abroad. The public can be encouraged to write and the documents verified by the SUHAKAM team before publishing. By this means, the practice of positive "Freedom of Speech" would motivate more ideas gathered and immediate action taken. The aggressive movement of SUHAKAM will outride the need for a new establishment to take care of human rights in Malaysia. SUHAKAM should continue its struggle to ratify human rights conventions signed by the Malaysian government. Besides, proposed policies, plans, programs and measures designed to reinforce and protect human rights; and implement these in coordination with the concerned parties. 


\section{Conclusion}

Like United Nations aspirations, a united global citizen could revolve around a culture of distinction, insistence, receptive, skilful, integrity, meritocracy, modesty, and loyalty. Since independence, attention to national harmony has prioritised unity in Malaysia's education, culture, socio-economy, political, regional, etc. The relations of all Malaysians regardless of racial, religious or cultural backgrounds is progressing remarkably. The government was supposed to sustain its responsibilities honourably and be honest with the public. In response, the people expected to reciprocate by placing their faith and confidence in the government, knowing that they would act in their best interests. In addition, human rights and equality before the law, which are essential concerns for the general public, must be upheld. The public requires confidence that nothing is beyond the law or above the reach of the law. The regulations must inspire confidence in them by recognising and protecting their rights. The data presented in this report serve as a baseline going forward. From time to time, a similar survey on a shorter to a more considerable extent reappearance so that stakeholders could evaluate the effects of different studies. Moving forward, additional research efforts on certain civil, political, economic, social, and cultural rights deserve greater attention, likewise issues particular to children and persons with disabilities. Students general opinions would be a limitation, but narrower, more focused studies in the future create room for specific detailing.

\section{Acknowledgements}

The authors want to express gratitude to all the respondents who have generously contributed to this study funded by Saramedia Global Sdn Bhd, Sarawak, Malaysia.

\section{References}

Abiddin, N. Z., \& Ismail, A. (2021). Gender and labour force participation in Malaysia: Current research and future direction on gender egalitarianism. International Journal of Academic Research in Progressive Education and Development, 10(2), 348-360. http://dx.doi.org/10.6007/IJARPED/v10-i2/9791

Aminnuddin, N.A. (2020). Ethnic differences and predictors of racial and religious discriminations among Malaysian Malays and Chinese. Cogent Psychology, 7(1):1-18 https://doi.org/10.1080/23311908.2020.1766737

Arab States-UNDP (2014). Enhancing National Human Rights Capacity in Yemen. https://www.arabstates.undp.org/content/rbas/en/home/library/Dem_Gov/human-rights-publicawareness-survey-in-yemen.html

Baqutayan S. M. S. (2020). Women empowerment is needed to boost gender equality in Malaysia. Current Research Journal of Social Sciences and Humanities, 3(1). 97-109. http://dx.doi.org/10.12944/CRJSSH.3.1.09

Chen, L.K. \& Koh, E.H. (2021). mySay: Leveraging gender equality to advance Malaysia's digital economy.The Edge Malaysia. https://www.theedgemarkets.com/article/mysay-leveraginggender-equality-advance-malaysias-digital-economy

Chung, N. (2021). Malaysia told to speed up reforms for gender equality. Free Malaysia Today. https://www.freemalaysiatoday.com/category/nation/2021/03/05/malaysia-told-to-speed-upreforms-for-gender-equality/

Hui, T.B. (2020). Monitoring Report: Gender Equality in Malaysia. Federation of Reproductive Health Associations, Malaysia (FRHAM). https://arrow.org.my/wp-content/uploads/2021/01/GenderEquality-In-Malaysia-.pdf

Jalal,N., Baskaran, R., Rajoo,N.T., Prathaban, S.N., Ambalagan, P. (2020). Gender equality at the workplace: Malaysia's stance and prevailing challenges. International Journal of Innovation and $\begin{array}{lll}\text { Business } & \text { Strategy, } & \text { 56-77. }\end{array}$ https://business.utm.my/ijibs/attachments/article/116/IJIBS_14_02_05.pdf

Kim, K.K., Abdullah, M.S., Kheng, M.Y.O. (2007). A brief introduction to Human Rights Commission of Malaysia (SUHAKAM). Malaysian Journal of Human Rights, 1(1):iii-xiii. 
https://drive.google.com/file/d/0B6FQ7SONa3PRVHF5Q0FGd0pLa1U/view?resourcekey=0c0p_rRhSjp29HmV0rTBNcA

Krejcie, R. V., \& Morgan, D. W. (1970). Determining Sample Size for Research Activities. Educational and Psychological Measurement, 30(3), 607610. https://doi.org/10.1177/001316447003000308

Lim, B. F. Y. (2018). Changes in Employment Structure in Malaysia: The Way Forward." Japan Labor Issues 2(8): 77-84.

Lim, B. F. Y. (2019). Women left behind? Closing the gender gap in Malaysia. Japan Labor Issues, 3(17): 22-29

OECD. (2017). The Pursuit of Gender Equality: An Uphill Battle. Paris: OECD Publishing.

Saleh, N.S.S.N., Ismail, W.A.F.W. \& Shukur, S.A. (2020). Rebranding Equality: Malaysia's Progress on Women's Rights Advocacy. International Journal of Islamic Thought 18: 85-94. https://doi.org/10.24035/ijit.18.2020.184

Saleh, N. S. S.N, Shukor, S.A., \& Ismail, W. A. F.W. (2021). Equality and citizenship for women in Malaysia: Where and when?. Malaysian Journal of Syariah and Law, 9(1), 103 - 113. https://doi.org/10.33102/mjsl.vol9no1.265

Thijs, P., Grotenhuis, M. T., Scheepers, P., \& Van den Brink, M. (2019). The Rise in Support for Gender Egalitarianism in the Netherlands,1979-2006: The Roles of Educational Expansion, Secularisation and Female Labor Force Participation. Sex Roles, 81: 594-609. https://doi.org/10.1007/s11199-019-1015-z

Weimann-Sandig, N. (2020). Malaysia and Its Transition Process Towards More Gender Equality at the Labor Market. Malaysian Journal of Social Sciences and Humanities, 5(7), 7 - 22. https://doi.org/https://doi.org/10.47405/mjssh.v5i7.441

World Economic Forum (2020). Global Gender Gap Report 2020. http://www3.weforum.org/docs/WEF_GGGR_2020.pdf

World Economic Forum (2021). Global Gender Gap Report 2021. http://www3.weforum.org/docs/WEF_GGGR_2021.pdf 